\title{
EN VÍSPERAS DE LA INDEPENDENCIA, DOS ILUSTRADOS LIGADOS AL VIRREINATO DEL PERÚ: BALTASAR JAIME MARTÍNEZ COMPAÑÓN Y BUJANDA (1738-1797) YJUAN FRANCISCO DE LA BODEGA Y QUADRA (1744-1794)
}

\author{
Concepción Reverte Bernal \\ Universidad de Cádiz
}

\begin{abstract}
Resumen: Este artículo compara brevemente la vida y obras de dos hombres ilustrados, ligados al Virreinato del Perú, que secundaron las directrices reformistas de Carlos III: el Obispo de Trujillo, D. Baltasar Jaime Martínez Compañón y Bujanda (1738-1797) y el marino y explorador del Noroeste de América, D. Juan Francisco de la Bodega y Quadra (1744-1794).

Palabras clave: ilustración hispanoamericana, pensamiento y reformas ilustradas en Hispanoamérica, cultura hispanoamericana del siglo XVIII.

Abstract: This article compares briefly the life and works of two enlightened men, linked to the Viceroyalty of Peru, followers of Charles III reform guidelines: the Bishop of Trujillo, D. Baltasar Jaime Martínez Compañón y Bujanda (1738-1797), and the marine and explorer of the Northwest America, D. Juan Francisco de la Bodega y Quadra (1744-1794).

Keywords: Spanish American Enlightenment, Enlightenment thought and reforms in South America, XVIII century Spanish American culture.
\end{abstract}

Con la llegada de Carlos III al trono (1759-1788), la monarquía española emprende una serie de reformas ilustradas, que, sin embargo, no podrán frenar el descontento que generará la Independencia. Algunos súbditos acogieron con entusiasmo las directrices del monarca, creyendo en la posibilidad de mantener el régimen colonial mejorando la administración, como los dos personajes de los que me ocupo, que guardan similitudes entre sí.

En este período, el Virreinato del Perú vuelve a perder extensión y poder, al desgajarse del mismo el Virreinato del Río de la Plata (1776), con importantes consecuencias para el comercio. Con el Reglamento de Libre Comercio en 1778, se ampliará el tráfico entre los puertos peninsulares e indianos, suprimiéndose la Casa de Contratación en 1790. Se crean nuevas Compañías comerciales y se fundan Consulados para promover la agricultura, la ganadería y el comercio. 
El regalismo del monarca conduce a la expulsión de los jesuitas en 1767, tras lo cual el rey enviará Visitadores generales a Hispanoamérica en 1769, con objeto de emprender la reorganización de las órdenes religiosas, ordenando convocar Concilios de las iglesias locales. El hueco dejado por los jesuitas con su expulsión lo intentarán cubrir franciscanos, dominicos y agustinos, pero ello no impedirá una decadencia misional. Desde el punto de vista cultural, a estas alturas del siglo se mantiene agudizado el conflicto entre dos estilos artísticos y dos mentalidades. Los hombres ilustrados han adoptado la estética Neoclásica y admiran el Enciclopedismo francés, los más conservadores mantienen el Escolasticismo ligado al Barroco. Aunque la Inquisición siga generando temor, su peso será inferior. Hay un auge de los "saberes útiles", entre los que sobresalen las Matemáticas y la Medicina; en México se crea en 1768 el Real Colegio de Cirugía y en Lima posteriormente, con Unanue, en 1792, el Anfiteatro Anatómico. Por estos años se fundan los Colegios de Minería de México y Lima, con resultados desiguales, y las Sociedades Económicas de Amigos del País, creadas para el estudio de las cuestiones locales, serán focos independistas, como la Sociedad Académica de Amantes del País de Lima, responsable del prestigioso Mercurio Peruano (1791-1795).

El siglo XVIII es el siglo de las Expediciones científicas. En cada una de ellas iba un nutrido grupo de cosmógrafos, astrónomos, dibujantes, botánicos, etc. Como sintetiza Lucena Salmoral ${ }^{1}$ :

Con Carlos III las expediciones alcanzaron su pleno desarrollo. Este monarca decidió utilizar la ciencia para los propósitos políticos y económicos de la Corona, mandando unas 40 de ellas a América. Las más importantes fueron las 20 siguientes: D'Auteroche (1768-70) a California, Pando (1768-69) a Patagonia, Gil de Lemos (1768-69) a las Malvinas, Francisco Machado (1768-69) a Chiloé, González, Lángara y Hervé (1770) a la isla de Pascua, Bonaechea (177273) a Tahití, Pérez (1774) al Noroeste, Heceta y Bodega (1775) al Noroeste, Dombey-Ruiz Pavón (1777-87) al Perú, Piedra (1778-79) a Patagonia, Arteaga-Bodega (1779) al Noroeste, Viedma (1780-84) a Patagonia, Varela-Alvear-Azara-Aguirre (1782-800) al Uruguay y Paraguay, Mutis (1783-810) al Nuevo Reino de Granada, Córdoba (1785-86) a Magallanes, Cuéllar (178598) a Filipinas, Moraleda (1786-87) a la costa sur chilena, Sessé-Mociño (178797) a México, Córdoba (1788-89) a Magallanes, y Martínez-Haro (1780-89) al Noroeste. Cuatro de éstas buscaron la reestructuración de los recursos productivos y el resto, se enviaron a fronteras amenazadas por potenciales enemigos ingleses, rusos y portugueses, donde se pretendía asentar colonias españolas que utilizaran sus riquezas. [...] Durante el reinado de Carlos IV fue apagándose este interés. Pese a todo, se realizaron una treintena de expediciones, entre

1 M. Lucena Salmoral, en A. Ciudad, M. Lucena Salmoral, C. Malamud, Manual de Historia Universal, 10. Historia de América, Madrid, Historia 16, 387-388. Este artículo está escrito con la colaboración de mi hijo, Manuel Míguez Reverte, quien me ayudó en la recopilación de bibliografía. 
las que sobresalieron las de Mazarredo, a las Antillas (1792), Joaquín Fidalgo a Tierra Firme (1792-1805), Ciriaco de Cevallos al seno mexicano (1801), Vernazi y Cortázar a Filipinas (1801-2), los hermanos Heuland a Perú y Chile (1795-1800), y Bodega y Caamaño a la costa norte de Nueva España (1792). Humboldt quedó asombrado del esfuerzo realizado por la Corona, superior al de ninguna otra del mundo, y anotó que las tres expediciones botánicas a México, Nueva Granada y Perú habían costado más de 400.000 pesos.

Hispanoamérica no era ajena a los cambios que se iban produciendo en el resto del mundo. Con la continuada rivalidad entre españoles peninsulares y criollos se iría forjando el clima de ruptura, a través de la ideología liberal aprendida en Europa por los criollos y el influjo de las logias masónicas, la Revolución de Estados Unidos (1776) y la Revolución francesa (1789). Un tiempo después, la invasión napoleónica y la guerra de la Independencia en España, brindarían la ocasión propicia para los levantamientos hispanoamericanos.

Los Virreyes coetáneos a Martínez Compañón y Bodega y Quadra en el Perú serán: Don José Antonio Manso de Velasco, Conde de Superunda (1745-1761), durante cuyo mandato se destruyó la ciudad de Lima, por el terrible terremoto de 1746 y quien tuvo que empezar a sofocar levantamientos indígenas. Don Manuel de Amat y Junient (1761-1776), fiel ejecutor de las directrices de Carlos III, quien se ocupó de la expulsión de los jesuitas y reunió los colegios de San Felipe y San Martín constituyendo el Real Convictorio de San Carlos, que tuvo como Rector al ilustrado peruano Toribio Rodríguez de Mendoza. Don Manuel Guirior (1776-1780), don Agustín de Jáuregui y Aldecoa (1780-1784) y don Teodoro de Croix, Caballero de Croix (1784-1790). En Nueva España, Bodega y Quadra tratará principalmente a don Antonio María de Bucareli y Ursúa (1771-1779) y a don Juan Vicente de Güemes Pacheco de Padilla, segundo Conde de Revillagigedo (1789-1794), tenido como un gran gobernante.

\section{El Obispo de Trujillo Baltasar Jaime Martínez Compañón y Bujanda}

Baltasar Jaime Martínez Compañón y Bujanda, había nacido en la villa de Cabredo, en Navarra, el 10 de enero de 1738. Era hijo legítimo de Mateo Martínez Compañón, el mayorazgo, natural de Bernedo o de Angostina, en Álava, y de María Martínez de Bujanda, natural de Cabredo, donde se avecindó el matrimonio. Estudió las primeras letras en Cabredo y posteriormente latín en Quintana hasta los once años. Después pasó a estudiar con los mercedarios de Calatayud y Leyes y Cánones en las Universidades de Huesca y Oñate. En esta última Universidad alcanzó el grado de Doctor en Cánones, ganando a continuación la Beca de Jurista en el Colegio de Sancti Spiritus; allí también ocupó las Cátedras de Instituta y de Prima de Leyes y el Rectorado del Colegio y de la Universidad, siendo nombrado, por sus méritos, Apoderado ante la Corte de Madrid de la villa de Oñate para varios asuntos. Tras concluir sus estudios de 
Teología en Vitoria, recibió el presbiteriado en 1761. Lo hallamos en 1764 en el Colegio Mayor de San Bartolomé, en Salamanca, donde recibió la Beca de Jurista. En el mismo año pasa a Santander como Canónigo Doctoral de su Catedral, con 25 años de edad, y se desempeña como Juez Sinodal y Apoderado ante la Corte en 1766. En 1767 es presentado por el monarca Carlos III para la chantría de la Catedral de Lima, embarcándose rumbo al Perú ese mismo año desde Cádiz. En julio de 1768 tomó posesión de la plaza referida en Lima; en 1770 es nombrado Rector de Santo Toribio y dos años después primer Secretario del V Concilio Provincial limeño, cargos que desempeña con gran acierto, como para merecer ser nombrado por el Papa Pío VI Obispo de Trujillo, en 1778. Una vez consagrado Obispo, Martínez Compañón embarca para su diócesis, llegando a través del puerto de Huanchaco, próximo a la ciudad de Trujillo, en mayo de 1779. La toma de posesión del Obispo no pudo ser en la Catedral por haber sido destruida durante el terremoto de 1759 , Catedral que mandaría reconstruir el navarro durante su gobierno. Asimismo, el Obispo mandó reconstruir el seminario, también en ruinas, y trazó su programa de estudios.

Las cualidades del Obispo, expuestas por José Navarro², hicieron que el Obispo se dedicara con entusiasmo a su labor, emprendiendo la visita pastoral a su extenso obispado, de más de $200.000 \mathrm{~km}^{2}$, y que abarcaba las tres regiones naturales del Perú: costa, sierra y selva, desde la frontera del Ecuador hasta el río Santa y bahía de Chimbote, cercanos a la cordillera Blanca en el actual Departamento de Ancash, con elevadas cumbres. Su modelo fue Santo Toribio de Mogrovejo, al que declarará Patrono principal de la diócesis en 1790. La visita pastoral del Obispo tuvo dos etapas: los años 1780 a 1782 los dedicó a la ciudad de Trujillo, mientras que de 1782 a 1786, recorrió su interior, con las incomodidades que tal hecho suponía en aquel tiempo. En una nota del Obispo al Rey Carlos III, fechada el 1 de octubre de 1786, Compañón justifica su comportamiento diciendo:

Nadie mejor que V.M. comprende cuánto importa para el buen gobierno de los pueblos en lo espiritual y temporal, un perfecto y cabal conocimiento de su geografía y de su historia natural en quien los gobierna ${ }^{3}$.

En la Biblioteca del Palacio Real en Madrid se conservan los volúmenes de dibujos, mapas y planos que mandó hacer el Obispo a pintores anónimos indígenas mientras efectuaba su visita, valioso testimonio de cómo era la diócesis de Trujillo a finales del siglo XVIII. Entre los colaboradores se sabe que contó con

2 Tesón, laboriosidad, amor al estudio, sentido de la justicia, piedad, celo por la disciplina eclesiástica, clemencia, templanza, generosidad, prudencia, etc. En Navarro Pascual, J., "Vida y personalidad del Obispo Martínez Compañón”, en J. Navarro, J. Paz Velázquez, E. Puig, M. A. Seminario, P. Restrepo, J. Rosales, A. Rumiche, Vida y Obra del Obispo Martínez Compañón, Piura, Universidad de Piura, Facultad de Ciencias y Humanidades, 1991, pp. 932.

3 Cfr. Navarro, ibid., 29. 
el cartógrafo José Clemente del Castillo. Los planos y dibujos carecen de texto que los acompañe, salvo unas brevísimas palabras, aunque al parecer el Obispo quería escribir con ellos una Historia de su diócesis que no tuvo tiempo para redactar. Años más tarde, su sobrino José Ignacio Lecuanda publica en el Mercurio Peruano, en 1793 y 1794, unas "Descripciones geográficas de los partidos de Trujillo, Piura, Saña ${ }^{4}$, Lambayeque y Cajamarca”, que parecen relacionarse con las pretensiones del Obispo. La estructura de la obra sobre la diócesis de Trujillo de Martínez Compañón es la siguiente: En el vol. I se describe el territorio mediante láminas y estadísticas, con mapas de las provincias del Obispado y de sus ciudades principales, con un trazado de sus calles y edificios notables, incluyendo retratos de sus Obispos y otros personajes. En el vol. II, que es el más interesante, se da una valiosísima información etnológica; Porras Barrenechea comenta:

En muchos de sus apuntes hay no sólo una intención satírica, sino a veces una comprensión artística de determinados aspectos de la vida social, al punto que pudieran servir de bocetos para grandes cuadros o frescos como los de Diego Ribera en México o José Sabogal y Camilo Blas en el Perú

La información sobre las industrias y oficios humanos que se ofrece aquí es completísima e incluye las ocupaciones femeninas, juegos, deportes y danzas, recogiendo partituras musicales. Los vols. III-VIII presentan imágenes de la fauna y flora regional, que Porras Barrenechea ${ }^{6}$ relaciona con el entusiasmo naturalista despertado por la expedición de Ruiz y Pavón al Perú, en 1778. Finalmente, en el vol. IX, el Obispo refleja el material arqueológico que pudo ver en Trujillo durante el siglo XVIII, con las ruinas de la ciudad de Chan Chan y otras huacas, poblaciones y vestigios antiguos, añadiendo representaciones de momias, múltiples piezas de vestir, telas, huacos, instrumentos, joyas, etc. Junto a los dibujos, el propio Obispo mandó recoger algunas de esas piezas, las cuales fueron enviadas a España cumpliendo la Instrucción que encargaba a las autoridades eclesiásticas y civiles recoger ejemplares de los tres Reinos a fin de formar con ellos un Gabinete de Historia Natural en Madrid; actualmente algunos de dichos objetos se encuentran expuestos de forma dispersa en el Museo de América de Madrid.

Todo lo dicho hasta aquí muestra la mentalidad ilustrada del Obispo. El interés por sus fieles en los aspectos espiritual y material y su afán reformador se reflejan asimismo en escritos dirigidos al Rey Carlos III, donde propone la

4 En estos años la rica ciudad de Zaña o Saña se hallaba ya destruida, como consecuencia de la piratería y de la gran inundación de 1720 , que produjo su abandono, con gran consternación en todo el Virreinato.

${ }^{5}$ R. Porras Barrenechea, La obra del Obispo Martinez Compañón sobre Trujillo del Perú en el siglo XVIII, Madrid, Ediciones Cultura Hispánica del Centro Iberoamericano de Cooperación, 1978, 29.

6 Ibid., 32. 
concentración de los habitantes diseminados, para facilitar su educación y sostenimiento, y otras medidas; por ej.:

Lo que únicamente se necesita es aumentar y hacer más útil su población, y para conseguirlo, reducir a sus habitantes a sociedad; dar crianza a la niñez de ambos sexos, impulso a la agricultura y minería, movimiento y acción a su comercio y que se fomente la industria ${ }^{7}$.

Con una clara preocupación por los indígenas, el Obispo se compadece de sus penalidades, planeando su catequesis a través de Seminarios de operarios apostólicos, como él los llamón 8 y la fundación de granjas agrícolas, escuelas generales y de Artes y Oficios para ellos. Entre las cartas que dirige Martínez Compañón a su Majestad, varios de sus biógrafos resaltan la escrita el 15 de mayo de 1786, sobre su proyecto de construir sendos colegios de cholitos y cholitas; la carta empieza así:

Señor: Desde antes que saliese de esa Península a servir la Chantría de Lima, a que V. M. se dignó proveerme de Canónigo Doctoral de Santander, el año pasado de 67 , creía así por lo que había leído como por lo tenía oído acerca de las calamidades y desdichas que padecen los indios de las Américas, ser infeliz su suerte en lo general, pero nunca juzgué que lo fuese tanto como después me lo ha demostrado la experiencia de casi 19 años de este Reino con continua intervención por uno y otro respeto en asuntos y negocios de dichos indios y una imparcial y atenta observación de todas sus incidencias y circunstancias, principalmente y más que todo la visita personal que acabo de hacer de las 12 provincias de valles, sierras y montañas que comprende este vasto Obispado y de todas y cada una de las matrices de sus curatos y de casi todos sus anejos, y aun haciendas.

A la verdad, Sr. los indios de este Obispado de que me toca y solamente voy a hablar por ahora, es una gente miserable sobre todo encarecimiento, por donde quiera que se mire. Ciertamente son miserables en sus almas, en sus cuerpos, en sus honras y en sus fortunas. En sus almas, por su profunda ignorancia y no tener idea del bien, del mal ni de la virtud y hallarse plagados y cancerados de vicios. En sus cuerpos, porque sanos y enfermos los tratan y son tratados con positiva indolencia, inhumanidad y crueldad, poniéndose por todas partes mil óbices y obstáculos a la conservación de su salud mientras la gozan, y ningún reparo ni auxilio para su restablecimiento cuando la pierden, ni aquellos que

7 T. de Arbeiza, Martinez Compañón, Pamplona, Diputación Foral de Navarra. Dirección de Turismo, Bibliotecas y Cultura Popular, [sin año de edición], 8.

8 R. Vargas Ugarte, Tres figuras señeras del episcopado americano, Lima, Editor Carlos Milla Batres, 1966, 182. Para el historiador jesuita, en sus desvelos por los indios Martínez Compañón solamente es equiparable al Obispo de Michoacán, D. Vasco de Quiroga.

9 Cito por J. M. Pérez Ayala, Baltasar Jaime Martínez Compañón y Bujanda. Prelado español de Colombia y el Perú 1737 1797, Bogotá, Imprenta Nacional, 1955, 272-273, modernizando la ortografía. 
comúnmente se suelen aplicar a las bestias. En sus honras, porque un mixto, el más desventurado, y aun tal vez un negro se quiere hacer superior al cacique más distinguido, si es que no llega a tratarle con vilipendio ultrajándole de palabra o con las manos. En sus fortunas, porque esta es para ellos, una voz vacía que no tiene significación, por lo cual ni saben mirar por sí ni por su posteridad, y siendo así que son si no los únicos, o a lo menos los que más trabajan sin comparación, vienen a ser los que menos fruto sacan de su sudor.

En otro fragmento de la misma carta el Obispo señala ${ }^{10}$ :

yo los tengo por iguales o muy poco diferentes a los demás hombres de su calidad en esta parte siempre que se lleguen a persuadir que el Señor los ha tratado con mucha misericordia y amor en haberlos redimido de la dura servidumbre que padecían bajo el imperio despótico de los Incas, que los conducía a una eterna perdición, y en ponerlos bajo del dulce, suave y justo gobierno de los Sres. Reyes de España, que en todos los tiempos han tratado como verdaderos padres, sin diferencia de los demás vasallos $[\ldots]$

En relación a estas ideas, con su paisano, el Virrey navarro Agustín de Jáuregui, se entendió bien, no así con su sucesor, el flamenco Teodoro de Croix y esto al parecer tuvo que ver con su destino a otra región americana. No podemos olvidar la coetaneidad de sus propuestas con el levantamiento indígena de Túpac Amaru de 1780, que llevaría incluso a la prohibición de los Comentarios Reales del Inca Garcilaso. El trabajo comenzado por el Obispo en la diócesis de Trujillo quedó truncado, pues en 1788 le llegó a Compañón su traslado a la sede metropolitana de Santa Fe, donde sería nombrado Arzobispo. Embarcado en Huanchaco, tomó posesión de su nuevo cargo en 1791. Allí se encontraría con otro de sus paisanos, el Virrey navarro don José de Ezpeleta y Galdeano, y acudiría a tertulias con el sabio naturalista José Celestino Mutis. Aunque en su nueva diócesis Compañón volvió a dar muestras de su laboriosidad, por su ya mermada salud, sólo pudo regirla durante seis años. Martínez Compañón falleció en 1797, siendo enterrado en la Catedral de Bogotá.

\section{El marino Juan Francisco de la Bodega y Quadra}

Juan Francisco de la Bodega y Quadra (o Cuadra), nació en Lima el 22 de mayo de $1744^{11}$. Era hijo legítimo de don Tomás de la Bodega y Quadra, español oriundo de Pobeña (hoy Muskiz, en Vizcaya, pueblo colindante con Santander), desde donde se había trasladado muy pronto a Lima por cuestiones familiares, y de doña Francisca de Mollinedo, criolla de ilustre familia, sobrina del Obispo Manuel de Mollinedo y Angulo, gran mecenas y reconstructor de la

10 Ibid., 273-274.

11 En alguna bibliografía aparece como fecha de nacimiento 1743, pero la partida de bautismo no ofrece dudas sobre el año. 
antigua capital del Imperio incaico tras el terremoto de 1650 . Su padre fue Alcalde electo y Cónsul del Tribunal del Consulado del Reino y tuvo otros cuatro hermanos y dos hermanas, los más famosos con él, Manuel Antonio, que fue Oidor y Alcalde del Crimen en Guatemala y Asesor del Virrey de Nueva España, y Tomás Aniceto, que fue Arcediano y Rector de la Universidad de San Marcos en Lima. En el Diccionario biográfico español de la Real Academia de la Historia, se dice que su familia era considerada la tercera en poder en el Virreinato del Perú y que su madre gustaba dar frecuentes fiestas, debilidad que heredó su hijo Juan Francisco, quien fue asimismo un magnífico anfitrión.

Juan Francisco estudia en Lima en el Real Colegio de San Martín, dependiente de la Universidad de San Marcos, después embarca junto a su hermano Manuel rumbo a España, donde aquel estudia Derecho en la Universidad de Alcalá de Henares, mientras Juan Francisco ingresa en la prestigiosa Escuela de Guardia Marinas de Cádiz, donde se encuentra desde 1762 hasta completar su formación, en 1767. En este periodo de tiempo embarca en los navíos Terrible, hacia aguas de Córcega, Princesa, hacia Nápoles, Palermo y Cartagena, y Garzota, rumbo a Civitavecchia, Córcega y Génova. Entre 1767 y 1773 Juan Francisco navega en el Ibicenco, Garzota y Septentrión, en este último a Buenos Aires, Concepción y Lima. De vuelta a España en 1773, fue elegido como uno de los oficiales destinados al Departamento de San Blas, en el Noroeste americano, cuando el Ministro de Estado Jerónimo Grimaldi así lo dispuso. Tras prepararse para su misión en España, el grupo salió del puerto de Cádiz en diciembre de 1774, desembarcando en el puerto novohispano de Veracruz, desde donde Juan Francisco se dirigió al pueblo de Tepic, en espera de la misión.

Bodega y Quadra participó en tres expediciones al Noroeste americano, en 1775,1779 y 1792, dejando escritos diarios de ellas junto con importantes mapas y tablas de navegación. Hay que tener en cuenta que las expediciones ilustradas eran una vía de ascenso económico y social durante el XVIII, como lo fueron las de la conquista durante los primeros siglos coloniales ${ }^{12}$. El estilo de los diarios de Bodega y Quadra es en general sobrio; en ellos el marino hace constantemente hincapié en su deseo de actuar al servicio de la Corona, como corresponde a alguien de su clase ${ }^{13}$ :

12 Salvador Bernabéu Albert: "Bodega y Quadra o el instante frágil en el Noroeste, un retrato inacabado", en Nutka 1792. Viaje a la Costa Noroeste de la América Septentrional por Juan Francisco de la Bodega y Quadra, del orden de Santiago, Capitán de Navio de la Real Armada y Comandante del Departamento de San Blas, en las fragatas de su mando Santa Gertrudis, Aránzazu, Princesa y Goleta Activa. Año de 1792, edición de M. Palau, F. Tovell, P. Sprätz y R. Inglis, Ministerio de Asuntos Exteriores de España, Dirección General de Relaciones Culturales y Científicas, 20-31.

13 Cito los diarios por la edición siguiente: J. F. de la Bodega y Quadra, El descubrimiento del fin del mundo (1775 1792), edición, introducción y notas de S. Bernabéu Albert, Madrid, Alianza, 1990. Una excepción que hace pensar en cómo podría haber sobresalido en otro tipo de escritos: "Desde la separación de la isla he notado que el cielo se muestra nublado, los horizontes cargados, dejándose ver el sol pocas veces; los rocíos, que desde San Blas han sido fuertes, enteramente han cesado; los vientos vienen muy fríos y se mantienen con poca fuerza hasta la oposición de la 
sólo miraba al deseo de corresponder con honor al encargo a que he venido, sacrificando mi salud y aun mi vida por Su Majestad.

A mí se me ha entregado su mando, yo debo cumplir con el orden, digo con el honor, que corresponde a mi nacimiento. [...] Dios esfuerza y ayuda las acciones grandes, $y$ cuando me sea la fortuna tan adversa que no encuentre remedio, morir cada uno en su ejercicio y por el Rey es gloria para la posteridad. pues los trabajos que he pasado y espero son indispensables a todo navegante, principalmente a los descubridores, y deben recibirse con conformidad y entereza, pues son por el servicio del Rey y honor de la Nación ${ }^{14}$.

Otros aspectos del relato de estas expediciones a parajes remotos hacen pensar en las crónicas de Indias, como la curiosidad y observaciones puntuales de los expedicionarios, comparando lo que descubren con lo que conocen de otros lugares de España y América, su descripción de la toma de posesión de los territorios, o incisos para encarecer sus méritos o justificar su conducta.

El Noroeste americano fue la última zona costera templada explorada por europeos. En los reconocimientos de esa región compitieron españoles, franceses, rusos, ingleses y norteamericanos. El Tratado de Tordesillas (1494) había dividido la conquista del Nuevo Mundo entre españoles y portugueses, y España se consideraba poseedora de derechos sobre las tierras del Noroeste todavía sin explorar. El galeón español de Manila, procedente de Nueva España, había llegado entonces a los $40-45^{\circ}$ de latitud. Los franceses de Canadá habían avanzado hasta las Montañas Rocosas, donde se detuvieron. El danés Vitus Behring, enviado por Rusia, había emprendido un viaje en 1741-1742 que lo había llevado hasta las costas americanas; los rusos, atravesando y conquistando Siberia, habían establecido una base en Kamchatka (actual Alaska), desde donde bajaban hacia el Sur, por órdenes del Zar e interés de particulares que comerciaban con pieles. Ingleses y norteamericanos exploraban asimismo la región en busca de sus riquezas; los viajes del Capitán Cook por la zona habían sembrado la inquietud en España. El territorio de Nutka (o Nootka) se consideraba español desde que el marino mallorquín Juan Pérez, a bordo de la fragata Santiago, había llegado a sus costas en 1774, llamando al lugar San Lorenzo. El motivo inicial de las expediciones ordenadas por Carlos III hacia el Noroeste fue detener el avance de los rusos, después tomar posesión de los territorios explorados por España, hasta que el Convenio firmado en El Escorial, en 1790, frenó el avance español beneficiando a los ingleses ${ }^{15}$.

luna, experimentando una entera mutación del temperamento menos en las corrientes, que siempre llevan su dirección al sur", 65 .

14 Ibid., 57, 68, 87-88.

15 Entre otra bibliografía destaco Mercedes Palau Baquero: "Presencia española en la costa del Noroeste, 1774-1796", en El Ojo del Totem. Arte y cultura de los indios del Noroeste de América, [Catálogo de la exposición Centro Cultural de la Villa. Madrid. Abril Mayo 1988. Museu Etnológic. Barcelona. Junio Julio 1988], Madrid, Comisión Nacional Quinto Centenario, 1988, 86-123. 
La expedición del Noroeste de 1775, salida de San Blas, se hizo con dos barcos: la fragata Santiago, comandada por Bruno de Heceta, jefe de la expedición, y la goleta Sonora, inicialmente comandada por otro oficial que tuvo un repentino ataque de locura y donde iba embarcado de la Quadra como segundo comandante, lo que hizo que quedara entonces al mando. En esta goleta iba también embarcado el piloto gallego Francisco Mourelle de la Rúa. En esta ocasión, mientras la fragata Santiago alcanzó los $47^{\circ}$ Norte (hoy Grays Harbor), la goleta Sonora, mucho más endeble, se aventuró a los $59^{\circ}$, hasta las proximidades del actual Sitka, en Alaska, haciendo mapas de su recorrido, lo cual produjo una gran satisfacción al Virrey de Nueva España, Bucareli. Tras esta actuación Bodega y Quadra fue ascendido a teniente de navío y el Virrey le ordenó trasladarse a Perú a comprar otro navío, con el fin de preparar la siguiente expedición al Noroeste, lo que hace viajando de vuelta con la fragata la Favorita.

La segunda expedición en la que participa de la Quadra sale en febrero de 1779. En esta ocasión comanda la expedición el teniente Ignacio de Arteaga, con la fragata Princesa, al que acompaña Bodega, con la fragata Favorita, y el propósito es alcanzar el paso del Norte entre los dos océanos. Ambas fragatas alcanzan los $61^{\circ}$ Norte, en Alaska, tomando posesión de tierras en nombre de España y trazando los mapas correspondientes, pero no pueden lograr su misión porque el mal tiempo y las dificultades de la ruta las hacen retornar. A su vuelta tienen noticia de la declaración de guerra a Inglaterra, pues Carlos III había decidido intervenir con Francia apoyando la independencia de las trece colonias de Norteamérica, la cual durará hasta la firma del Tratado de Versalles en 1783, y de la repentina muerte del Virrey Bucareli, gran valedor de estas empresas. Bodega es ascendido a capitán de fragata en 1780, recibiendo órdenes de viajar al Callao para traer azogues y pertrechos de guerra para Nueva España, lo que efectúa entre 1781 y 1783. A su vuelta le llega la orden de trasladarse a La Habana, lo que cumple embarcándose en Veracruz. Tras esto, a petición propia, se dirige a España, donde permanece entre 1785 y 1788, periodo del que se tienen escasas noticias. Quadra envía cartas a la Corte solicitando un nuevo destino en América, ambicionando el mando del Departamento de San Blas desde donde salían las expediciones al Noroeste, y en un escrito de 1787 da cuenta de sus deseos de contraer matrimonio en Tepic con la hija de Miguel Marín del Valle, casamiento que, al parecer, no llega a efectuar por razones que se desconocen, permaneciendo toda su vida soltero. En marzo de 1789 Carlos IV nombra a Bodega Comandante del Departamento de San Blas, tal como requería, siendo elegidos seis oficiales para acompañarlo: Jacinto Caamaño, Manuel Quimper, Salvador Fidalgo, Ramón Saavedra, Francisco de Eliza y Salvador Menéndez Valdés; entre ellos Quimper será el que mantenga una relación más estrecha con él, siendo ambos limeños ${ }^{16}$.

16 Manuel Quimper explorará el estrecho de Fuca. Véase Eric Beerman, "Manuel Quimper y Bodega y Quadra. Dos limeños al servicio de la Real Armada”, en Nutka 1792, op. cit., 32-43. 
Entretanto, para frenar el avance de otras potencias, España había enviado al Noroeste una expedición al mando de Esteban José Martínez, quien, una vez llegado a Nutka, toma posesión del lugar sin tener en consideración navíos norteamericanos que se encontraban allí y enfrentándose a los ingleses, cuyos barcos apresa cuando llegan; este incidente es aprovechado por la diplomacia inglesa para declarar la guerra a España, guerra que impide el Conde de Floridablanca para evitar la ruina económica y al no poder hacer efectivo el Pacto de Familia con Francia, por hallarse este último estado en plena Revolución. La crisis con Inglaterra termina con el Convenio de El Escorial, firmado en octubre de 1790, claramente desfavorable para España, pues los españoles se comprometen a no sobrepasar Nutka y devolver este lugar a los ingleses, pues estos últimos alegaban derecho al territorio al haber comprado una pequeña porción de tierra al cacique Macuina. Otras exploraciones españolas siguieron a la de Martínez: de Francisco de Eliza, Manuel Quimper, de navíos de la expedición de Malaspina.

La misión encomendada a Bodega y Quadra en su tercera expedición, de 1792, será recorrer las costas españolas del Noroeste, fijando los límites con los ingleses en Nutka. Para fortalecer las posiciones españolas y preparar su misión, entre 1790 y 1792 se construyen en San Blas, bajo las órdenes de Bodega, cuatro goletas: Valdés, Sutil, Mexicana y Activa. La expedición de límites se emprende en 1792, llevando consigo Bodega las fragatas Santa Gertrudis, Nuestra Señora de Aránzazu y Princesa, la corbeta Concepción y las goletas Activa y Saturnina. Bodega llega a Nutka el 29 de abril de 1792 y allí debe esperar al jefe de la representación inglesa, que será el capitán de fragata George Vancouver, quien arriba a finales de agosto. Con gran tacto diplomático y a costa de su propio capital, Bodega negocia con los ingleses agasajándolos con invitaciones en las que participa el propio jefe nativo Macuina, de tal manera que Vancouver, quince años más joven que él, se convierte en su amigo y le propone sellar su amistad poniendo al lugar, en vez del topónimo indígena Nutka, el nombre de "Isla de Bodega y Quadra y Vancouver", nombre que con el paso del tiempo perderá su primera parte quedando abreviado como Vancouver. La propuesta de Bodega y Quadra y Vancouver a sus respectivos gobiernos es que, mientras no se decida de otro modo, Nutka debería continuar como posesión española, lo que supone una victoria diplomática de Bodega y Quadra que no durará mucho tiempo, pues poco después España concederá Nutka a los ingleses ${ }^{17}$.

Como consecuencia de sus servicios, el nuevo Virrey, llegado a la Nueva España a la par que de la Quadra, el Conde de Revillagigedo, propone a la Corona que se conceda al marino la Encomienda de la Orden de Santiago y un nuevo ascenso. A la vuelta de esta misión de límites, de la Quadra se siente cansado y enfermo, a cuya curación no ayuda el clima insalubre de San Blas donde permanece en su puesto hasta que solicita permiso para tratarse, dejando la plaza a cargo de Quimper. De la Quadra viaja con dos criados a México. Sintiéndose

17 Véase F. Tovell, “Rivales y Amigos. Quadra y Vancouver”, en Nutka 1792, op. cit., 72-85. 
muy débil, hace testamento en Guadalajara en noviembre de 1793 y, acompañado además por su amigo, el cirujano jubilado de la Real Armada Pedro de Carvajal, marcha a Ciudad de México donde fallece el 26 de marzo de 1794, siendo enterrado allí en el convento de San Fernando.

José María Madueño, en el Diccionario biográfico español de la Real Academia de la Historia, concluye sobre su figura ${ }^{18}$ :

Diversas son las razones por las que se ha convertido en el más famoso marino español del noroeste: su participación en diversas expediciones; sus diarios se encuentran entre los más importantes de toda la presencia española en la zona, tanto por su interés científico como por sus valores literarios; sus dotes de mando y sus arriesgadas navegaciones.

Sus escritos más importantes son diarios y relaciones de viajes, inapreciables para estudiar las costumbres de los naturales de la costa norteamericana.

La serie de cartas geográficas que trazó, y que se encuentran en el Archivo General de Indias de Sevilla y en el Museo Naval de Madrid, le dan categoría de gran cartógrafo.

De la misma manera, Antonio Menchaca Careaga sostiene ${ }^{19}$ :

El nombre del capitán de navío Juan Francisco de la Bodega Quadra se inscribe por derecho propio en esta relación de nuestra Ilustración. En efecto, y como hombre ilustrado fue polifacético, explorador, colonizador, cartógrafo, hidrógrafo, astrónomo, naturalista, botánico, escritor, diplomático y humanista, sin perder su condición de valeroso navegante.

En relación a los pueblos indígenas del Noroeste de América, José Alcina Franch resumía ${ }^{20}$ :

En la costa cuyas características ambientales acabamos de definir y en algunas zonas costeras limitadas de más al sur, en los estados de Washington y Oregón, se asentaron una serie de grupos indígenas, que, en conjunto, representan una de las culturas más singulares y homogéneas de toda Norteamérica. De acuerdo con las lenguas habladas por esos grupos se pueden establecer una serie de stocks lingüísticos bien diferenciados. Los grupos Tlingit y Haida los más septentrionales del área- juntamente con los Atapascos forman el stock lingüístico Na-dené. Los Tsimshian, junto con los Chinook, del estado de Washington, se unen a la gran familia Penutian. Los Kwakiutl y Nootka forman el grupo Wakash; los restantes grupos — Comox, Cowichan, Klallam,

18 J. M. Madueño Galán, “Bodega y Cuadra Mollinedo, Juan Francisco de la”, en Diccionario biográfico español, vol. VIII, Madrid, Real Academia de la Historia, 2009, 598.

19 "Juan Francisco de la Bodega y Quadra y su tiempo", en Nutka 1792, op. cit., 4.

20 "La cultura de los indios de la Costa del Noroeste", El Ojo del Totem, op. cit., 48-85, la cita en 50 . 
Suuqualmi, Twana, Quileute y Quinault- constituyen el grupo Salish, que junto al grupo Wakash, viene a formar el gran conjunto Algonquino-wakash.

Los indígenas de esta zona, boscosa y de difícil acceso para la navegación, vivían del mar, trasladándose en canoas y dedicados a la pesca, sobre todo del salmón. Se refugiaban en casas de madera y en el aspecto religioso y festivo llamaban la atención sus tótemes. Sobresalían también haciendo máscaras y artículos de cestería, como los vistosos sombreros que reflejan los dibujos antiguos. Algunos de los objetos de estas culturas del Noroeste que se encuentran en el Museo de América de Madrid fueron obtenidos en la expedición Malaspina, pero también a través de Bodega y Quadra ${ }^{21}$. El trato humano que brindaba de la Quadra a los indios facilitó sus expediciones. A través de la lectura de sus diarios se observa una progresión en su aproximación a ellos, distinguiendo a los indios que se les acercaban con docilidad y "cariñosamente" de los que resultaban violentos, a los que califica de "bárbaros". Ricardo Melgar Bao utiliza su primer diario para explicar, entre otros aspectos, la importancia del regalo y trueque en los contactos con los indígenas. En el diario de su tercer viaje dice el marino peruano en un determinado momento ${ }^{22}$ :

Podría acaso lisonjearme de que, tratando a estos indios como deben tratarse los hombres y no como a individuos de inferior naturaleza, he vivido en el seno de la tranquilidad

El caso más claro de ello fue la relación de amistad que mantuvo con el cacique indígena de Nutka, Macuina, que iba más allá de las diferencias étnicas y culturales.

\section{Sintesis final}

Una vez presentadas estas dos figuras históricas, se puede establecer el paralelo entre sus personalidades y su modo de obrar ilustrado. Baltasar Jaime Martínez Compañón y Juan Francisco de la Bodega y Quadra nacieron y murieron con una escasa diferencia de años, y ambos, por el destino y por su nacimiento respectivamente, estuvieron ligados al Virreinato del Perú. Ambos eran de origen noble y procedían por parte paterna de familias del norte de España. En los dos casos pasaron algunos años de su vida en Lima, capital del Virreinato, $y$, dadas las dimensiones de la ciudad de entonces (unos miles de habitantes) y su clase social, debieron de tratar a un mismo núcleo de personas. Ambos tendrían noticia de los sucesos relevantes que afectasen a la sociedad peruana,

21 R. Melgar Bao, "Juan Francisco de la Bodega y Quadra: etnografía y navegación en el Pacífico americano (siglo XVIII)”, Convergencia. Revista de Ciencias Sociales, UAEM, Núm. Esp. IA2009, 261.

22 Op. cit., 179. 
como pudieron ser la expulsión de los jesuitas de España y sus colonias, las condiciones y actuaciones de los Virreyes o la rebelión de Túpac Amaru, en 1780. Ambos, en su comportamiento, son conscientes de su condición de nobles y actúan de acuerdo con su nacimiento, siendo leales al monarca Carlos III, con el que se identifican especialmente por su formación ilustrada. Los dos son hombres valientes, aplicados y diligentes y defienden con sus dedicaciones los intereses de la Corona española, rindiendo cuentas al Rey a través de cartas. Los dos se imponen a sí mismos el cumplimiento de sus obligaciones ligadas a sus respectivos oficios, sin parar en la salud quebrantada; así, Martínez Compañón se trasladará obedientemente a la diócesis de Santa Fe y Bodega y Quadra permanecerá enfermo en la Comandancia de San Blas hasta obtener el permiso para abandonarla. Ambos serán personas muy generosas con sus subalternos y con sus bienes particulares, siendo buenos administradores de los bienes públicos y en el ejercicio de sus respectivas misiones, hasta el punto de acabar sus días escasos de hacienda personal por este motivo. Los dos hubieron de pasar un tiempo en España y recorrer diversas zonas de América, principalmente Lima, Trujillo y Santa Fe de Bogotá, en el caso de Martínez Compañón, Buenos Aires, Lima, Veracruz, Ciudad de México, Monterrey y San Blas, en el caso del marino peruano; esto les daría a los dos una perspectiva amplia sobre las cuestiones relativas al Imperio español, al no limitarse al conocimiento de una sola región. Los dos sienten interés por los aspectos locales hispanoamericanos, recogiendo observaciones gráficas y manuscritas sobre lo que encuentran a su paso; en este sentido, el interés por planos y estadísticas del Obispo de Trujillo se viene a corresponder con los mapas y tablas de navegar del marino limeño; en ambos este modo de actuar es reflejo de su formación científica, que exige la recopilación de datos constatables. Los dos hacen apreciaciones etnológicas avant la lettre y recogen muestras de campo en forma de objetos que harán enviar a España y que se conservan en el Museo de América de Madrid. Los dos mantuvieron un trato digno con los indígenas, Martínez Compañón pensando en la mejora de sus condiciones de vida y Bodega y Quadra haciendo unas exploraciones al Noroeste sin incurrir en combates innecesarios y ganándose su confianza, como sucedió con el cacique nutka Macuina. Los dos murieron fuera de sus lugares de origen y la memoria de sus aportaciones se fue olvidando con el paso del tiempo, hasta que empiecen a ser recordados a partir del siglo XX en diferentes lugares. Los dos merecen reconocimiento en el siglo XXI por haber sido hombres ilustrados e ilustres, que supieron desempeñar los papeles de su vida con hombría de bien.

\section{BIBLIOGRAFÍA}

Ciudad, A., Lucena Salmoral, M. y Malamud, C., Manual de Historia Universal, 10. Historia de América, Madrid, Historia 16, 1992. 
Mendiburu, M. De, Diccionario histórico biográfico del Perú, segunda edición con adiciones y notas bibliográficas publicada por E. San Cristoval, Lima, Imprenta "Enrique Palacios", 1932.

Milla Batres, C., Diccionario histórico y biográfico del Perú, Lima, Editorial Milla Batres, 1986.

Vargas Ugarte, R., Historia General del Perú, Lima, Editorial Carlos Milla Batres, 1981.

\section{Baltasar Jaime Martinez Compañón}

Arbeiza, T. DE, Martínez Compañón, Pamplona, Diputación Foral de Navarra. Dirección de Turismo, Bibliotecas y Cultura Popular, [sin año de edición].

Ballesteros Gaibrois, M., "El obispo Martínez Compañón, el último ilustrado en América”, Arqueología, Antropología e Historia en los Andes. Homenaje a María Rostworowski, ed. R. Varón Gabai,J. Flores Espinoza, Lima, Instituto de Estudios Peruanos, Banco Central de Reserva del Perú, 1997, 133-150.

López Serrano, M., Trujillo del Perú en el siglo XVIII, Madrid, Editorial Patrimonio Nacional, 1976.

Martínez Compañón, Trujillo del Perú [ed. facsímil], 9 vols. y 3 vols. de apéndices, Madrid, Agencia Española de Cooperación Internacional, Ediciones de Cultura Hispánica, 1998 [Primera tirada: 1978].

Navarro Pascual, J., "Vida y personalidad del Obispo Martínez Compañón", en Navarro, J., Paz Velázquez, J., Puig, E., Seminario, M. A., Restrepo, P., Rosales, J., Rumiche, A., Vida y Obra del Obispo Martinez Compañón, Piura, Universidad de Piura. Facultad de Ciencias y Humanidades, 1991, 9-32.

Pérez Ayala, J. M., Baltasar Jaime Martínez Compañón y Bujanda. Prelado español de Colombia y el Perú 1737 1797, Bogotá, Imprenta Nacional, 1955.

Porras Barrenechea, R., La obra del Obispo Martínez Compañón sobre Trujillo del Perú en el siglo XVIII, Madrid, Ediciones Cultura Hispánica del Centro Iberoamericano de Cooperación, 1978.

Restrepo, D., La Iglesia de Trujillo (Perú) bajo el Episcopado de Baltasar Jaime Martínez Compañón (1780 1790), 2 vols., Vitoria Gasteiz, Eusko Jaurlaritzaren Argitalpen Zerbitzu Nagusia Servicio Central de Publicaciones, Gobierno Vasco, 1992.

VARgas Ugarte, R., Tres figuras señeras del episcopado americano, Lima, Editor Carlos Milla Batres, 1966.

\section{Juan Francisco Bodega y Quadra}

Bodega y QuAdRA, J. F. DE LA, El descubrimiento del fin del mundo (1775 1792), edición, introducción y notas de S. Bernabéu Albert, Madrid, Alianza, 1990.

Соок, W. L., "Bodega y Quadra (Cuadra), Juan Francisco de la", Dictionnary of Canadian Biography Online, 17711800 (Volume IV), www.biographi.ca (consltado 112 2010).

Dunbar Temple, E., "Apostillas sobre el marino limeño Juan Francisco Bodega-La Quadra y Mollinedo", en Actas del Primer Simposio de Historia Marítima y Naval Iberoamericana, ed. J. Ortiz Sotelo, Lima, Fondo de Publicaciones de la Dirección de 
Intereses Marítimos. Instituto de Estudios Históricos Marítimos del Perú, 1993, 389-395.

Madueño Galán, J. M., "Bodega y Cuadra Mollinedo, Juan Francisco de la”, Real Academia de la Historia, Diccionario biográfico español, vol. VIII, Madrid, Real Academia de la Historia, 2009, 592-599.

Melgar Bao, R., "Juan Francisco de la Bodega y Quadra: etnografía y navegación en el Pacífico americano (siglo XVIII)", Convergencia. Revista de Ciencias Sociales, UAEM, Núm. Esp. IA2009, 259-273.

Nutka 1792. Viaje a la Costa Noroeste de la América Septentrional por Juan Francisco de la Bodega y Quadra, del orden de Santiago, Capitán de Navio de la Real Armada y Comandante del Departamento de San Blas, en las fragatas de su mando Santa Gertrudis, Aránzazu, Princesa y Goleta Activa. Año de 1792, Edición de Mercedes Palau, Freeman Tovell, Pamela Sprätz y Robin Inglis, Ministerio de Asuntos Exteriores de España. Dirección General de Relaciones Culturales y Científicas, Depósito legal: M 3832998.

El Ojo del Totem. Arte y cultura de los indios del Noroeste de América, [Catálogo de la exposición Centro Cultural de la Villa. Madrid. Abril Mayo 1988. Museu Etnológic. Barcelona. Junio Julio 1988], Madrid, Comisión Nacional Quinto Centenario, 1988. 